\title{
SURVEY DAN ANALISIS SEISMISITAS WILAYAH JAWA TIMUR BERDASARKAN DATA GEMPA BUMI PERIODE 1999-2013 SEBAGAI UPAYA MITIGASI BENCANA GEMPA BUMI
}

\author{
Jihan Nia Shohaya, Uswatun Chasanah, Afifi Mutiarani, Lilik Wahyuni P, \\ Madlazim \\ Jurusan Fisika, FMIPA Universitas Negeri Surabaya \\ e-mail : jihanniashohaya@gmail.com
}

\begin{abstract}
Abstrak
Kajian kegempaan suatu wilayah terutama di daerah rawan gempa bumi seperti Jawa Timur sangat diperlukan dalam rangka mengurangi dampak yang ditimbulkan akibat bencana gempa bumi. Dalam konteks ini, dilakukan penelitian yang bertujuan untuk menganalisis tingkat seismisitas di wilayah Jawa Timur antara tahun 19992013 yaitu dengan menganalisis hubungan antara frekuensi kejadian gempa bumi $(N)$ dan magnitudo gempa bumi (M). Rumus umum yang digunakan, yaitu log $N=a$ - bM. Gradien persamaan ini atau nilai b merupakan parameter tektonik yang menggambarkan sifat batuan pada daerah yang diteliti sedangkan nilai a menggambarkan aktivitas tektonik wilayah yang diamati. Data yang digunakan dalam penelitian ini merupakan data sekunder parameter gempa bumi dari bank data seismologi IRIS dengan magnitudo 4,0-10,0 SR pada kedalaman 0-200 km yang berlokasi antara $110^{\circ}-115^{\circ}$ BT dan $5^{\circ}-10^{\circ}$ LS. Berdasarkan hasil analisis dengan metode maximum likelihood, didapatkan besarnya parameter seismisitas untuk wilayah 1 diperoleh nilai a sebesar 11,7 dan nilai b sebesar 1,86. Sementara untuk wilayah 2 diperoleh nilai a sebesar 9,69 dan nilai b sebesar 1,49. Hasil analisis menunjukkan bahwa wilayah 1 memiliki tingkat seismitas yang lebih besar dibandingkan wilayah 2. Sedangkan nilai b pada kedua wilayah relatif sama. Hal tersebut menunjukkan bahwa batuan pada wilayah Jawa Timur memiliki heterogenitas yang rendah.
\end{abstract}

Kata kunci : Seismisitas, Gempa Bumi, Jawa Timur

\section{Abstract}

Studying about seismicity pattern, especially in earthquake prone areas such as East Java is needed in order to reduce the impact caused by the earthquake. This research is analyze the level of seismicity and the return period of earthquakes by analyzing the relationship between the frequency of occurrence of earthquakes $(N)$ and the earthquake magnitude (M). The main formula is $\log N=a-b M$, gradient equation or $b$ value describes the nature of tectonic rocks of observed regions, and a value describes the tectonic activity of observed regions. This research is used secondary data of earthquake from seismology data bank IRIS from 1999 to 2013 that have magnitudes 4,0 - 10,0 SR on depth 0-200 km located within latitude coordinates between $11^{\circ}-115^{\circ} \mathrm{E}$ and $5^{\circ}-10^{\circ} \mathrm{S}$. Based on the results of the analysis using maximum likelihood method, for region 1 obtained that a value is about 11,7 and $b$ value is about 1,86. While for region 2 obtained that a value is about 9,69 and and $b$ value is about 1,49. The analysis result points out that region 1 have greater seismicity patern than region 2. But the $b$ value between two regions are same. This fact indicated that the rocks on East Java has low heterogeneous.

Keywords : Seismicity, Earthquake, East Java 


\section{PENDAHULUAN}

Dinamika tektonik pulau Jawa didominasi oleh pergerakan lempeng Indo-Australia yang relatif bergerak ke utara bertumbukan dengan lempeng Eurasia yang relatif diam. Penunjaman lempeng Indo-Australia berkisar 100-200 km di bawah dan $600 \mathrm{~km}$ di utara pulau Jawa. Tunjaman lempeng tersebut mengakibatkan pergerakan unsur-unsur. Kondisi ini menjadikan wilayah pulau Jawa sebagai daerah tektonik aktif dengan tingkat seismisitas yang tinggi. Sehinnga secara langsung wilayah Jawa Timur khususnya juga mengalami pergerakan lempeng yang aktif pula. Dengan posisi geodinamika tersebut perlu adanya upaya antisipasi berupa peringatan gempa bumi untuk mengurangi dampak yang ditimbulkan akibat bencana gempa bumi.

Ada beberapa upaya antisipasi sejak dini, salah satunya yaitu berupa peringatan gempa bumi untuk mengurangi dampak yang ditimbulkan akibat bencana gempa bumi baik materi maupun jiwa manusia. Yaitu dengan analisis tingkat seismisitas pada daerah yang bersangkutan. Salah satu cara untuk menganalisis aktivitas seismik suatu daerah dalam upaya mitigasi adalah dengan menganalisis hubungan antara frekuensi kejadian gempa bumi dan magnitudo gempa bumi (Frequency-Magnitudo Disribution) ${ }^{[7]}$.

Penelitian ini difokuskan pada keadaan aktivitas seismik berdasarkan analisis statistik keadaan, nilai indeks seismisitas di wilayah Jawa timur.

Apabila terdapat dua buah gaya yang bekerja dengan arah yang berlawanan pada batuan kulit bumi, maka batuan tersebut akan terdeformasi atau mengalami perubahan bentuk. Hal ini dikarenakan batuan mempunyai sifat elastis. Apabila gaya yang bekerja pada batuan dalam waktu yang lama dan terus menerus, maka lama kelamaan daya dukung pada batuan akan mencapai batas maksimum dan akan mulai terjadi pergeseran ${ }^{[4]}$.

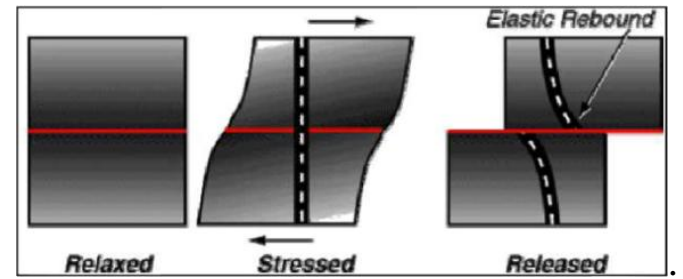

Gambar 1. Proses deformasi batuan yang mengakibatkan terjadinya gempa bumi ${ }^{[4]}$.

Akibatnya batuan akan mengalami patahan secara tiba-tiba sepanjang bidang fault. Setelah itu batuan akan kembali stabil, namun sudah mengalami perubahan bentuk dan posisi. Pada saat batuan mengalami gerakan yang tiba-tiba akibat pergeseran batuan, energi stress (Gambar 1) yang tersimpan akan dilepaskan dalam bentuk getaran yang kita kenal sebagai gempa bumi.

Parameter gempa bumi adalah acuan nilai besaran dan letak kejadian suatu gempa bumi. Besaran gempa bumi merupakan suatu ukuran kekuatan yang dihitung berdasarkan data dari alat perekam gempa atau seismograf.

Parameter gempa bumi tersebut meliputi :

1) Waktu kejadian gempa bumi

2) Hiposenter

3) Episenter

4) Kedalaman sumber gempa bumi

5) Kekuatan gempa bumi atau magnitudo.

Seismisitas pada saat ini dinyatakan sebagai suatu sistem data serasi yang dapat memberikan suatu gambaran atau informasi secara sistematis tentang karakteristik dan aktivitas gempa bumi pada suatu daerah dalam jangka waktu tertentu. Informasi itu dapat berupa suatu bentuk persamaan empiris, peta, grafik dan tabel. Informasi tentang tingkat seismisitas suatu daerah tidak lepas dari kevalidan data yang dianalisis serta kurun waktu yang digunakan untuk analisis.

Kurun waktu yang singkat dalam pengambilan data sulit dipakai pedoman untuk 
menentukan aktivitas gempa bumi di suatu daerah dengan baik. Tetapi apabila dalam waktu yang singkat tersebut dapat memberikan informasi data gempa bumi yang banyak, maka penetuan tingkat seismisitas suatu daerah dianggap cukup akurat.

Salah satu cara untuk menganalisis aktivitas kegempaan suatu daerah dalam upaya mitigasi adalah dengan menganalisis hubungan antara frekuensi dan magnitude ${ }^{[7]}$.

Magnitudo merupakan ukuran kekuatan gempa bumi, menggambarkan besarnya energi yang terlepas pada saat gempa bumi terjadi dan merupakan hasil pengamatan seismograf.

Rumus umum yang banyak dipergunakan untuk tujuan menganalisis hubungan antara frekuensi dan magnitudo ini berasal dari rumus empiris yang diturunkan oleh B. Gutenberg dan C.F. Richter adalah sebagai berikut:

$$
\log \mathrm{N}(\mathrm{M})=a-b \mathrm{M}
$$

Dimana $\mathrm{N}$ merupakan frekuensi kejadian gempa bumi dan $M$ adalah magnitudo, serta $a, b$ adalah konstanta.

Nilai $a$ menunjukkan keaktifan seismik daerah yang dipengaruhi oleh tingkat kerapuhan batuan. Nilai tingkat seismisitas di suatu daerah yang sedang diamati tergantung dari :

1) Periode pengamatan,

2) Luas daerah pengamatan, dan

3) Aktivitas seismik daerah yang diamati.

4)

Semakin besar nilai $a$ di suatu daerah berarti daerah tersebut memiliki aktivitas seismik yang tinggi, sebaliknya untuk nilai $a$ yang kecil berarti aktivitas seismiknya rendah. Sedangkan nilai $b$ menunjukkan kemiringan atau gradien dari persamaan linier hubungan frekuensi kejadian gempa bumi dan magnitudo. Nilai ini erat sekali hubungannya dengan tektonik daerah yang sedang diamati dan tergantung dari sifat batuan setempat dan menggambarkan aktivitas stress lokal.

Dengan kata lain, nilai- $b$ adalah parameter tektonik yang menunjukkan jumlah relatif dari gempa bumi yang kecil hingga gempa bumi besar, nilai ini mendekati 1 yang berarti 10 kali penurunan aktivitas terkait dengan kenaikan dalam tiap unit magnitudo.

\section{METODE PENELITIAN}

Penelitian tentang analisis tingkat seismisitas periode 1999-2013 wilayah Jawa timur ini dikerjakan dengan metode maximum likelihood

Data yang digunakan dalam penelitian ini merupakan data sekunder, yaitu parameter gempa bumi, yang terdiri dari: kejadian, letak episenter (latitude dan longitude), kedalaman, magnitudo gempa bumi. Data tersebut diperoleh dari portal data seismologi IRIS (Incorporated Research Institutions for Seismology), dengan magnitudo 4,0-10,0 SR dan kedalaman 0-200 $\mathrm{km}$. Dengan daerah penelitian berlokasi di $110^{\circ}-115^{\circ}$ BT dan $5^{\circ}-10^{\circ} \mathrm{LS}$, yang diunduh melalui situs

(http://www.iris.edu/SeismiQuery/sq-events.htm)

Tahapan pengolahan data adalah sebagai berikut:

1) Menghimpun data parameter gempa bumi sesuai dengan kriteria data yang telah ditentukan (magnitudo, kedalaman, letak astronomis wilayah, dan event kajadian gempa bumi)

2) Mengkonversi seluruh magnitudo gempa bumi menjadi magnitudo momen $(M w)$, hal ini dilakukan karena magnitudo momen tidak mengalami saturasi, berdasarkan pada persamaan tabel berikut:

Tabel 1.Persamaan konversi magnitude momen ${ }^{[2]}$.

\begin{tabular}{|c|l|}
\hline No & $\begin{array}{c}\text { Persamaan Konversi Magnitudo } \\
\text { Momen }\end{array}$ \\
\hline 1 & $M w=0,1403 M s^{2}-1,051 M s+7,285$ \\
\hline 2 & $M w=0,1140 m b^{2}-0,556 m b+5,560$ \\
\hline 3 & $M w=0.787 M E-1.537$ \\
\hline 4 & $m b=0,125 M L^{2}-0,389 M L-3,513$ \\
\hline 5 & $M L=0,717 M D+1,003$ \\
\hline
\end{tabular}


3) Membagi wilayah penelitian menjadi 2 bagian berdasarkan garis bujur

4) Memfilter data gempa bumi dengan tujuan untuk menghilangkan pengaruh foreshock dan aftershock sehingga diperoleh gempa bumi utama dengan software Z-MAP 6.0 (Ngatmanto, 2009)

5) Menganalisis data hasil decluster dengan metode maximum likelihood untuk mengitung parameter seismisitas.

6) Dan pada tahap akhir yaitu memetakan distribusi persebaran episenter gempa bumi dengan perangkata lunak ArcView GIS 3.3.

Hasil analisis data yang diperoleh yaitu nilai $a, b$, dan standar deviasi digunakan untuk mengetahui tingkat seismisitas yang terjadi pada daerah penelitian. Kemudian dibuat suatu grafik hubungan atau korelasi magnitudo dan besarnya frekuensi gempa bumi. Grafik korelasi tersebut kemudian diinterpretasikan sesuai bahwa nilai konstanta $a$, dan $b$ berkaitan langsung dengan karakteristik seismisitas wilayah yang diteliti.

\section{HASIL DAN PEMBAHASAN}

Daerah yang akan ditentukan parameter keaktifan seismik yaitu $a$, dan $b$ adalah wilayah Jawa Timur yang terletak pada antara $110^{\circ}-115^{\circ}$ BT dan $5^{\circ}-10^{\circ}$ LS. Periode yang digunakan dalam penelitian ini yaitu antara tahun 19992013. Pembagian wilayah ini dilakukan untuk melakukan perbandingan tingkat seismisitas. Wilayah 1 terletak pada $110,02^{\circ}-112,49^{\circ}$ BT dan $5^{0}-10^{\circ}$ LS sedangkan untuk wilayah 2 terletak pada $112,5^{\circ}-114,95^{\circ} \mathrm{BT}$ dan $5^{\circ}-10^{\circ} \mathrm{LS}$. Pembagian wilayah dilakukan karena distribusi zona gempa atau pola aktifitas kegempaan pada masing-masing wilayah Jawa Timur berbedabeda.

Berdasarkan peta sebaran episenter atau pusat gempa bumi wilayah Jawa Timur hasil pemetaan sebaran lokasi gempa bumi atau episenter dengan menggunakan software Arc
View GIS 3.3 (Gambar 2), dalam kurun waktu 14 tahun terjadi 495 gempa bumi, setelah difilter dengan tujuan untuk menghilangkan pengaruh gempa pendahuluan (foreshock) dan gempa susulan (aftershock) dengan software ZMAP 6.0 sehingga diperoleh 330 gempa bumi utama. Masing masing pada wilayah 1 terdapat 109 gempa bumi utama dan 221 gempa bumi utama pada wilayah 2. Terlihat bahwa pusatpusat gempa terdistribusi sebagian besar di daerah lautan selatan Jawa Timur atau laut Jawa. Sedangkan pusat gempa di daratan adalah di sepanjang wilayah selatan Jawa Timur, yaitu kabupaten Pacitan, Ngawi, Kediri, Malang, Jember dan Banyuwangi, sementara untuk kabupaten lain di bagian utara wilayah Jawa Timur jarang terjadi gempa bumi.

Penggambaran pada peta tersebut di dasarkan pada letak episenter gempabumi tiap daerah pada wilayah Jawa Timur. Titik merah menandakan letak episenter gempa bumi pada wilayah 1, sedangkan untuk titik ungu menandakan letak episenter pada wilayah 2 . Dari gambar diatas dapat dilihat bahwa gempagempa yang terjadi pada wilayah 1 lebih besar dan lebih banyak dibandingkan dengan wilayah 2. Sehingga aktivitas seismik sering terjadi pada wilayah 1 dibandingkan pada wilayah 2 .

Setelah data episenter gempa bumi dipetakan seperti gambar 2 diatas, data-data parameter gempa bumi yang terdiri dari garis lintang, garis bujur, tanggal, waktu, magnitudo, dan kedalaman gempa bumi kemudian dimasukkan kedalam perangkat lunak z-map dengan format atau ekstensi *txt untuk dianalisis parameterparameter seismisitas di Jawa Timur. Berikut ini merupakan hasil analisis parameter-parameter gempa bumi dengan metode maximum likelihood. Berikut ini merupakan hasil olah data dan anaisis dengan z-map. 


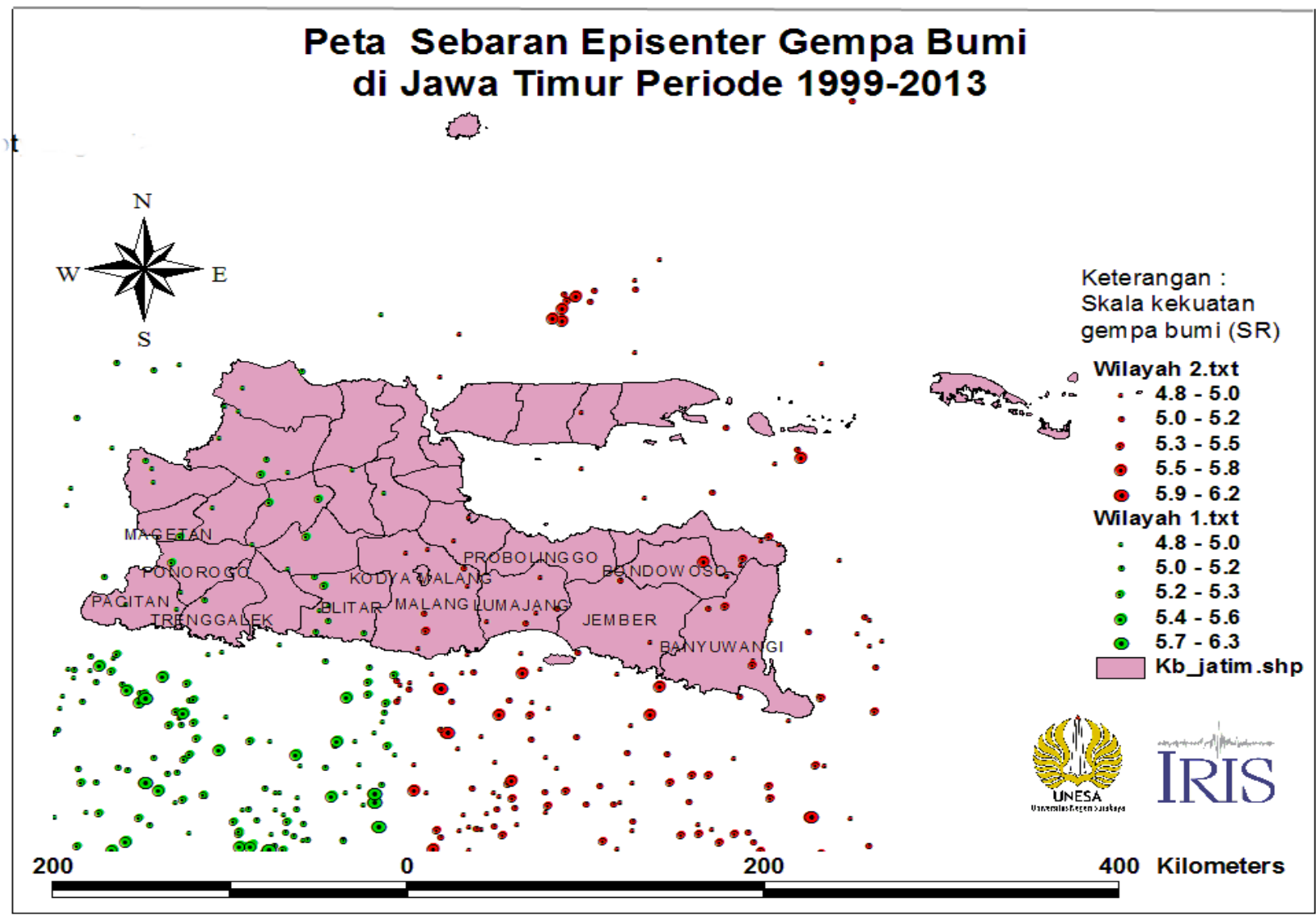

Gambar 2. Peta sebaran episenter gempa bumi Jawa Timur periode 1999-201

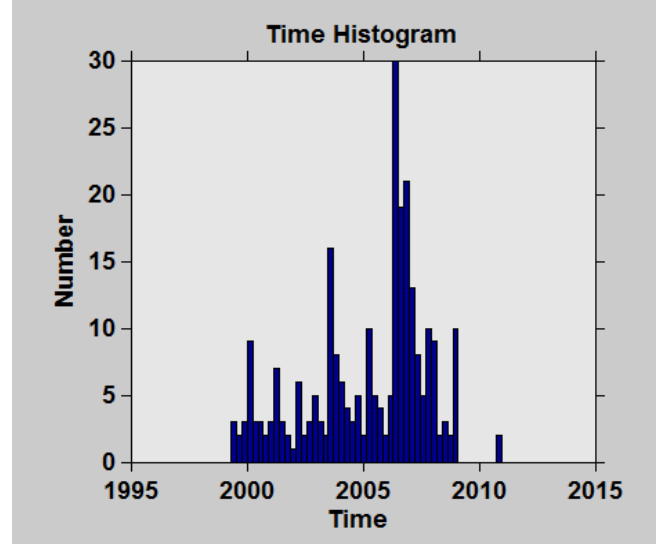

Gambar 3. Histogram distribusi frekuensi gempa bumi untuk rentang magnitudo 4,9-6,4 SR pada wilayah 1 Jawa Timur periode 1999-2013.

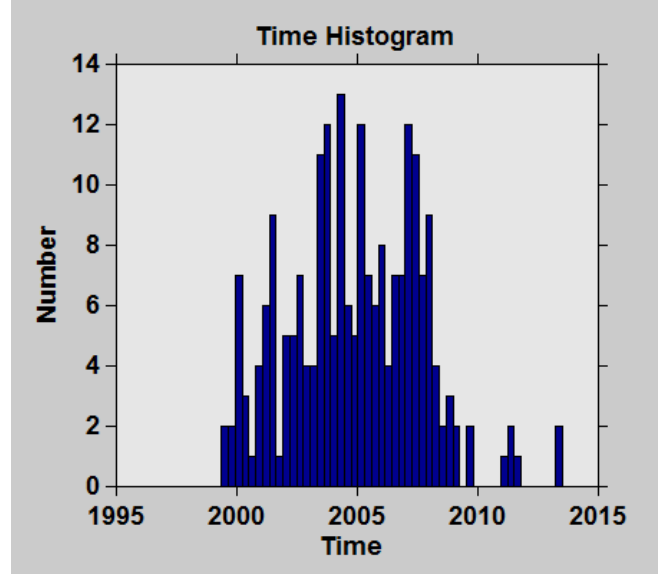

Gambar 4. Histogram distribusi frekuensi gempa bumi untuk rentang magnitudo 4,8-6,3 SR pada wilayah 2 Jawa Timur periode 1999-2013 .

Dari perbandingan histogram pada gambar 3 dan 4, yaitu frekuensi kejadian gempa bumi pada kurun waktu 14 tahun yaitu antara tahun 1999-2013. Pada umumnya gempa bumi 
banyak terjadi pada rentang waktu 2000-2010. Pada wilayah 1 , gempa bumi terbanyak terjadi pada tahun 2006 yaitu sebanyak 74 gempa bumi utama. Sementara untuk wilayah 2, gempa bumi paling banyak terjadi pada tahun 2007 sebnayak 35 gempa bumi utama. Drai histogram tersebut dapat dikatakan bahwa wilayah 2 sering mengalami kejadian gempa bumi daripada wilayah 1 .

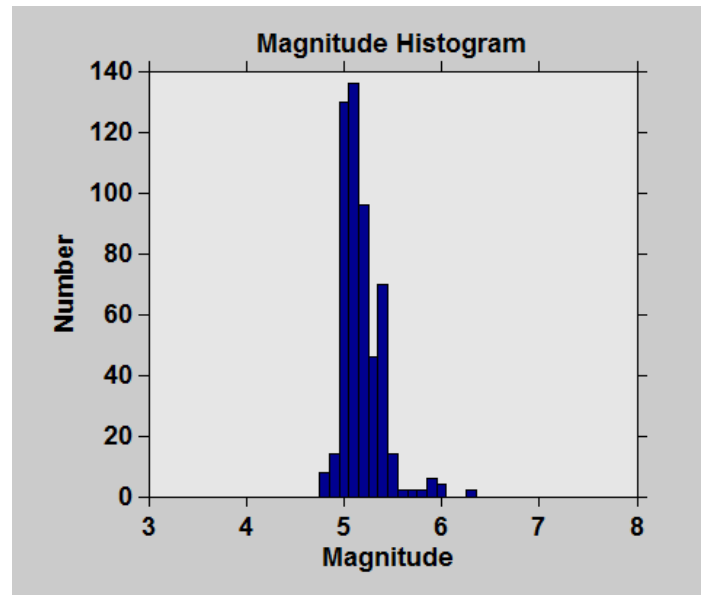

Gambar 5. Histogram distribusi frekuensi gempa bumi terhadap magnitudo wilayah 1 Jawa Timur periode 1999-2013

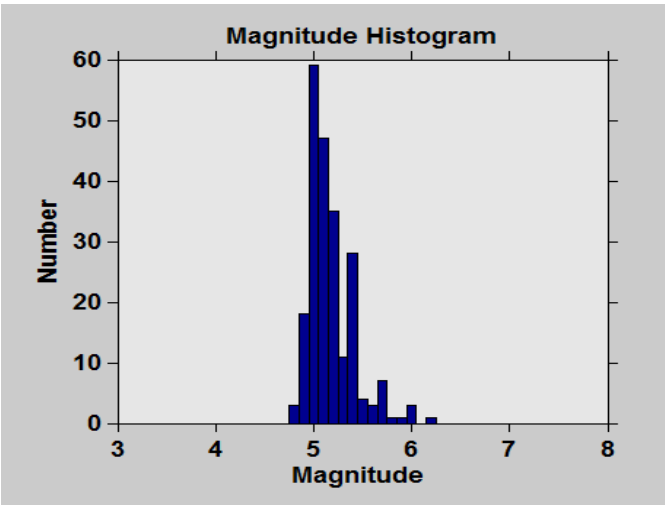

Gambar 6. Histogram distribusi frekuensi gempa bumi terhadap magnitudo wilayah 2 Jawa Timur periode 1999-2013.

Gempa bumi di wilayah Jawa Timur didominasi gempa bumi dengan magnitudo antara 4,8-5,5 SR (Gambar 5 dan 6). Rentang magnitudo gempa bumi tersebut tergolong gempa bumi merusak yang mengakibatkan kerusakan yang signifikan baik di daratan maupun lautan. Gempa bumi tersebut sering terjadi di lautan dari pada di daratan. Walaupun di wilayah Jawa Timur jarang terjadi gempa bumi dengan magitudo besar, wilayah ini tergolong wilayah yang mempunyai aktivitas kegempaan yang cukup tinggi. Hal ini dibuktikan dengan seringnya gempa bumi terjadi dalam kurun waktu 14 tahun terakhir.

Kecepatan gelombang seismik dipengaruhi oleh kekakuan dan kerapatan lapisan tanah sebagai medium bagi penjalaran gelombang. Kondisi atau struktur tanah mempengaruhi pola gelombang seismik yang pada akhirnya juga mempengaruhi besarnya magnitudo gempa bumi yang terjadi di wilayah Jawa Timur. Faktor-faktor litologi atau struktur bawah permukaan wilayah Jawa Timur. Struktur Geologi Jawa Timur di dominasi oleh Alluvium dan bentukan hasil gunung api kwarter muda, keduanya meliputi $44,5 \%$ dari luas wilayah darat, sedangkan bantuan yang relatif juga agak luas persebarannya adalah miosen sekitar 12,33 $\%$ dan hasil gunung api kwarter tua sekitar $9,78 \%$ dari luas total wilayah daratan. Sementara itu batuan lain hanya mempunyai proporsi antara $0-7 \%$.

Dengan kondisi litologi seperti itu, maka wilaiyah Jawa Timur rentan akan gempa bumi dan tanah longsor, mengingat usia batuan yang relatif muda. Terutama pada pada Wilayah Jawa Timur bagian selatan dan timur, dengan kondisi geografis bayaknya gunung api daripada wilayah Jawa Timur bagian utara.

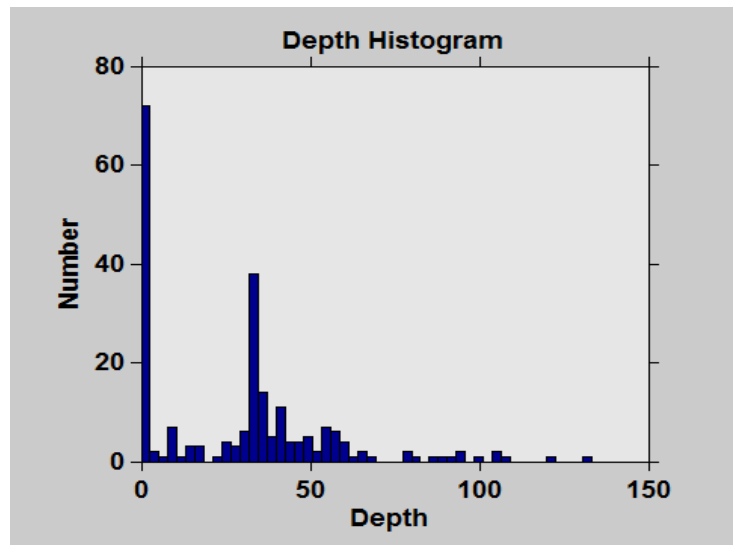

Gambar 7. Histogram distribusi frekuensi gempa bumi terhadap kedalaman untuk rentang magnitudo 4,9-6,4 SR wilayah 1 SR di Jawa Timur periode 1999-2013. 


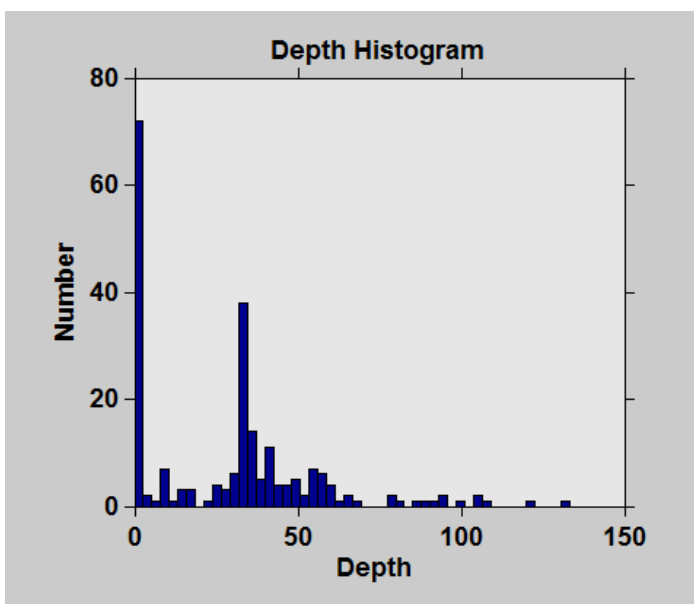

Gambar 8. Histogram distribusi frekuensi gempa bumi terhadap kedalaman untuk rentang magnitudo 4,8-6,3 SR di wilayah 2 periode 1999-2013.

Dari Gambar 8 dan 9 dapat dilihat bahwa pada umumnya gempa bumi sering terjadi pada kedalaman 30-39,3 km di bawah permukaan bumi untuk wilayah 1 , sementara pada wilayah 2 gempa bumi sering terjadi pada $3,0-49,7 \mathrm{~km}$ di bawah permukaan bumi. Gempa bumi pada kedalaman tersebut merupakan gempa bumi dangkal, yang terjadi di daratan maupun lautan wilayah Jawa Timur, namun lebih didominasi terjadi di lautan. Gempa dangkal merupakan gempa yang paling berbahaya, karena dengan magnitudo yang tidak seberapa besar akan dapat mengakibatkan kerusakan yang cukup besar.

\section{Hubungan Frekuensi Kejadian Gempa Bumi dengan Magnitudo}

Analisis grafik hubungan antara frekuensi kejadian gempabumi dengan magnitudo dilakukan pada dua wilayah yang telah dibagi. Pembagian wilayah dilakukan karena distribusi zona gempa atau pola aktifitas kegempaan pada masing-masing wilayah Jawa Timur berbedabeda. Berikut merupakan grafik hungan antara frekuensi kejadian gempa bumi dengan magnitude pada masing masing wilayah.

Berdasarkan gambar 10 dan 11 distribusi frekuensi magnitudo di atas dengan menggunakan metode maximum likelihood diperoleh parameter seismisitas secara umum untuk wilayah 1 nilai $a$ yaitu 11,7 sedangkan nilai $b$ yaitu 1,86. Sehingga relasi GutenbergRichter yang didapatkan adalah $\log \mathrm{N}=11,7-$ 1,86 M. Sementara untuk wilayah 2, diperoleh nilai $a$ yaitu 9,69 sedangkan nilai $b$ yaitu 1,49 . Sehingga relasi Gutenberg-Richter yang didapatkan adalah $\log \mathrm{N}=9,69-1,49 \mathrm{M}$. Nilai tersebut masing masing memliki stadar deviasi sebesar 0,24 dan 0,25.

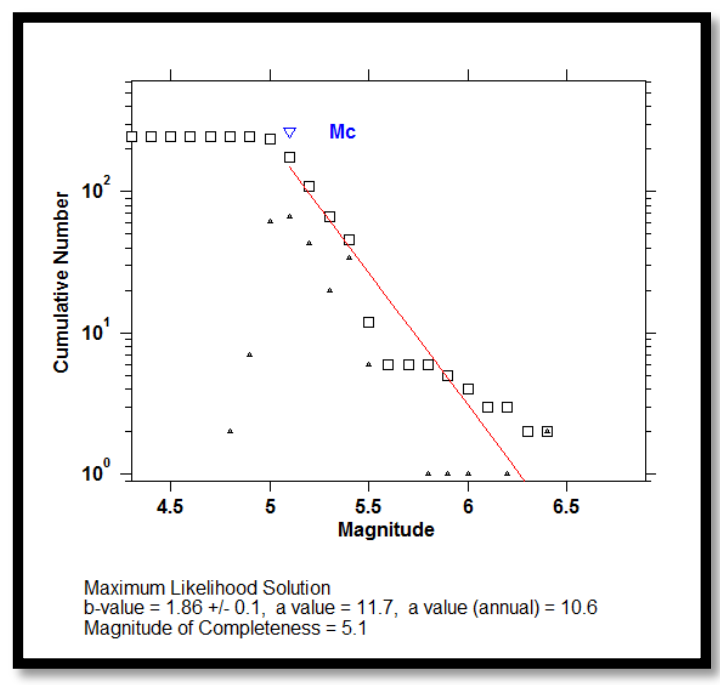

Gambar 9. Grafik distribusi frekuensi gempa bumi terhadap magnitudo untuk rentang magnitudo 4,9-6,4 SR di wilayah 1 periode 1999-2013.

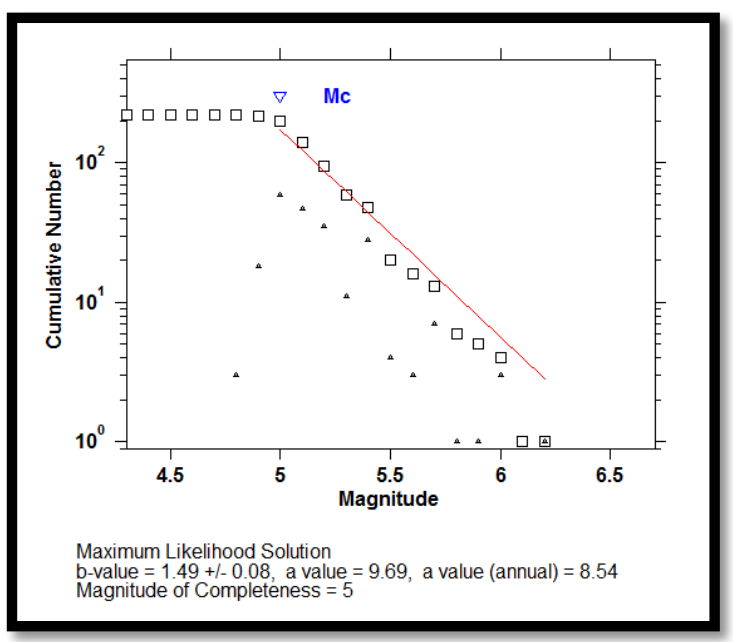

Gambar 10. Histogram distribusi frekuensi gempa bumi terhadap magnitudo untuk rentang magnitudo 4,8-6,3 SR di wilayah 2 periode 19992013.

Nilai $a$ menunjukkan tingkat keaktifan seismik, wilayah 1 dengan nilai $a$ sebesar 11,7 
yang menunjukkan wilayah 1 Jawa Timur memiliki aktivitas kegempaan yang tinggi dibandingkan dengan wilayah 2. Semakin besar nilai $a$ berarti semakin aktif wilayah 1 aktivitas kegempaannya. Sebaliknya untuk nilai $a$ yang kecil berarti aktivitas seismik pada wilayah 2 Jawa Timur juga kecil. Didapatkan nilai $b$ sebesar 1,86 , nilai $b$ menunjukkan kemiringan atau gradien dari persamaan linier hubungan frekuensi kejadian gempa bumi dan magnitudo. Nilai ini erat sekali hubungannya dengan keadaan tektonik daerah yang sedang diamati dan tergantung dari sifat batuan setempat dan menggambarkan aktivitas stress lokal, dalam hal ini adalah kerapuhan batuan.

Besarnya parameter ini bergantung banyaknya kejadian dan untuk wilayah tertentu bergantung pada penentuan luas wilayah serta kurun waktu pengamatan. Semakin besar nilai b berarti makin besar pula tingkat kerapuhan batuannya, begitu pula sebaliknya. Ditinjau dari hasil analisis nilai b yang didapatkan, batuan pada wilayah 1 maupun wilayah 2 Jawa Timur tergolong batuan yang rapuh (batuan yang heterogen), stress yang dikandung tidak besar karena langsung dilepaskan melalui tejadinya gempa-gempa kecil yang banyak yaitu berkisar 4,8-5,5 SR. Dengan kata lain untuk batuan yang lebih rapuh (heterogen), energi yang dikumpulkan tidak terlalu besar karena langsung dilepaskan dalam bentuk gelombang seismik.

Struktur geologi wilayah Jawa Timur terdiri dari berbagai macam batuan. Masing-masing memiliki jenis lapisan tanah yang berbeda, dan memiliki kekuatan respon terhadap tanah yang berbeda pula, dalam hal ini adalah lapisan permukaan, terhadap gelombang (gempa bumi). Besar kecilnya respon terhadap tanah atau penguatan gelombang dipengaruhi oleh densitas dan katebalan lapisan sedimen.

Batuan Alluvium Kuarter dan batuan sedimen berumur Tersier yang terkandung dalam struktur litologi wilayah Jawa Timur memiliki densitas atau rapat massa batuan yang besar. Nilai penguatan gelombang pada batuan wilayah Jawa Timur bertambah besar akibat batuan telah mengalami deformasi (pelapukan, pelipatan, pensesaran), sesar yang membentang di wilayah Jawa Timur yang mengubah sifat fisik batuan menjadi rapuh, dan mengakibatkan pula rapuhnya stuktur batuan di wilayah Jawa Timur.

Atas dasar struktur, sifat dan persebaran jenis tanah diidentifikasi karakteristik wilayah Jawa Timur menurut kesuburan tanah:

a) Jawa Timur bagian Tengah merupakan daerah subur, mulai dari daerah kabupaten Banyuwangi. Wilayah ini dilalui sungaisungai Madiun, Brantas, Konto, Sampean.

b) Jawa Timur bagian Utara merupakan daerah Relatif tandus dan merupakan daerah yang persebarannya mengikuti alur pegunungan kapur utara mulai dari daerah Bojonegoro , Tuban kearah Timur sampai dengan pulau Madura.

\section{PENUTUP}

\section{Simpulan}

Berdasarkan hasil penelitian dan pembahasan, maka dapat ditarik kesimpulan sebagai berikut:

1. Besarnya parameter seismisitas wilayah Jawa Timur pada periode 1999-2013, pada wilayah 1 diperoleh nilai a sebesar 11,7 dan nilai $b$ sebesar 1,86, dengan rentang magnitudo 4,9-6,4 SR. Gempa bumi terbesar diwilayah ini terjadi pada tanggal 26 Mei 2006 dengan magnitudo 6,4 SR dan pada kedalaman $19,9 \mathrm{~km}$ dari atas permukaan bumi. Sementara untuk wilayah 2 diperoleh nilai a sebesar 9,69 dan nilai b sebesar 1,49, dengan rentang magnitudo 4,8-6,3 SR. Gempa bumi terbesar diwilayah ini terjadi pada tanggal 13 Oktober 2011 dengan magnitudo 6,3 SR dan pada kedalaman $39 \mathrm{~km}$ dari atas permukaan bumi. Hasil analisis statistik dengan metode Maximum likelihood menunjukkan bahwa nilai a pada wilayah 1 lebih besar dibandingkan dengan wilayah 2. Hal ini berarti wilayah 1 memiliki tingkat seismitas yang lebih besar 
dibandingkan wilayah 2. Sedangkan nilai b pada kedua wilayah relatif sama. Hal tersebut menunjukkan bahwa batuan pada wilayah Jawa Timur memiliki heterogenitas yang rendah.

2. Secara umum dapat disimpulkan bahwa wilayah Jawa Timur secara keseluruhan memiliki tingkat seismisitas tinggi yang dibuktikan dengan nilai parameter seismisitas yang tinggi dan seringnya terjadi gempa bumi dangkal pada kedalaman 30-39,3 km dengan magnitudo antara 4,8-5,5 SR yang dapat mengakibatkan kerusakan yang cukup signifikan, terutama di wilayah daratan.

\section{Saran}

Dalam penelitian tentang survey dan analisis seismisitas wilayah Jawa Timur dalam kurun waktu 14 tahun dari tahun 1999 sampai dengan tahun 2013 ini ditemukan berbagai kendala dalam menentukan parameter keaktifan seismik yaitu a, b, dan pemetaan episenter gempa bumi. Berikut ini merupakan saran untuk mengatasi masalah yang muncul dalam perhitungan data antara lain: (1) Perbandingan dengan metode lainnya selain metode Maximum likelihood juga sangat penting untuk mengetahui manakah metode yang paling akurat untuk analisis statistik tingkat seismisitas suatu wilayah. (2) Untuk memaksimalkan hasil penelitian sebaiknya data yang digunakan dalam kurun waktu lebih dari 10 tahun. (3) Karena penelitian ini menyangkut servey dan memerlukan data primer yaitu data yang diambil secara langsung, maka diperlukan perangkat atau alat untuk mencatat data primer, sehingga semakin valid hasil penelitian tersebut.

\section{UCAPAN TERIMA KASIH}

Tim Peneliti menyampaikan terima kasih kepada LPPM UNESA karena telah mendanai penelitian ini, serta peneliti menyampaikan terima kasih kepada IRIS (http://www.iris.edu/SeismiQuery.htm) yang telah menyediakan akses data seismologi, lebih lanjut penulis mengucapkan terimakasih kepada Wyss M, Wiemer, S, and Zúñiga, R, yang menyediakan akses opensource software ZMAP 6.0 untuk mengolah data penelitian penulis.

\section{DAFTAR PUSTAKA}

[1] Alabi, A. A., Akinyemi, O. D., Adewale, A. 2013. Seismicity Pattern in Southern Africa from 1986 to 2009. Earth Science Research Vol 2, No 2, 2013. Canadian Center of Science and Education. Canada

[2] Budiono, Ahmad. D. A. 2011. Evaluasi Peak Ground Acceleration untuk Peta Gempa Indonesia di Kota Padang. ITS Undergraduate Paper. (Online, diakses tanggal 5 Juli 2013).

[3] Edwiza, Daz. 2009. Kajian terhadap Indek Bahaya Seismik Regional Rata-Rata Jawa timur. Jurnal TeknikA, Laboratorium Geofisika Jurusan Teknik Sipil Unand Vol 1, No 29, 2009 (Online, diakses tanggal 6 Juni 2013).

[4] Hamidah, Mitra. 2011. Analisis Seismisitas dan Pemetaan Lokasi Persebaran Gempa Wilayah Jawa Timur Periode 1973-2010. Skripsi (yang dipublikasikan). Jurusan Fisika Universitas Islam Negeri Maulana Malik Ibrahim. Malang. (Online, diakses tanggal 5 Juli 2013).

[5] Kantor Pembangunan Nasional, Kantor Wilayah Jawa Timur. 2012. Laporan Pembangunan Wilayah Jawa Timur. Surabaya: Badan pembangunan Nasional Wilayah Jawa Timur (Online, diakses tanggal 20 Juni 2013)

[6] Rusdin, Andi A. 2009. Analisa Statistik Seismitas Sulawesi Selatan dan Sekitarnya (Tahun 1938 - 2008). Jakarta: Akademi Meteorologi dan Geofisika (Online, diakses tanggal 5 Juli 2013)

[7] Rohadi, Supriyanto. 2010. Distribusi Spasial dan Temporal Seismotektonik Wilayah Subduksi Jawa. Balai Besar 
Meteorologi dan Geofisika Wilayah II Jakarta. Jakarta

[8] Wyss M, Wiemer, S. 2000. Minimum Magnitudo of Completeness in Earthquake Catalogs:Examples from Alaska, the Western United States, and Japan. Buletin of the Seismologycal Society of America 90, 4, pp. 859-869 August. (Online, diakses tanggal 18 Juli 2013).

[9] Wyss M, Wiemer, S, and Zúñiga, R. 2002. ZMAP A Tool For Analyses Of Seismicity Patterns, Typical Applications And Uses: A Cookbook. (Online, diakses tanggal 5 Juli 2013). 